[The Editors of the Journal of General Microbiology accept no responsibility for the Reports of the Proceedings of the Society. Abstracts of papers are published as received from the authors.]

\title{
THE SOCIETY FOR GENERAL MICROBIOLOGY
}

The Society for General Microbiology held its Sixty-first General Meeting at the University College London on Monday, Tuesday and Wednesday, 5, 6 and 7 April I97I. The following communications were made.

\section{ORIGINAL PAPERS}

\section{SYMPOSIUM: MICROBES AND BIOLOGICAL PRODUCTIVITY}

Substrate-accelerated Death: Role of Recovery Medium and Prevention by $3^{\prime}-5^{\prime}$ Cyclic AMP. By P. H. CALCOTT and J. R. Postgate (University of Sussex, Falmer, Brighton, BNI NQK)

Substrate-accelerated death is a phenomenon whereby the substrate, or some metabolic intermediate derived from it, whose exhaustion limited growth of the population being studied specifically accelerates death of the population in starvation conditions (see review by Postgate, J. R. (1967), Advances in Microbial Physiology 1, I).

We have studied substrate-accelerated death of populations from glycercol-limited chemostat of Aerobacter aerogenes starved in $0.13 \mathrm{M}-\mathrm{NaCl}+0.02 \mathrm{M}$-sodium phosphate, $\mathrm{pH} 7.4$, using the procedures described earlier (Postgate, J. R. \& Hunter, J. R. (I962), Journal of General Microbiology 29, 233; corrigenda: Journal of General Microbiology 34, 473), estimating viability by slide culture. A matrix of tests, in which glycerol, glucose and sodium pyruvate were assessed as accelerators of death and in which recovery media with each substrate as the major carbon energy source were tested, confirmed evidence for limited specificity: the growth-limiting substrate or a metabolite derived readily from it was necessary to accelerate death. We now report that glycerol-accelerated death was only expressed on recovery media based on glycerol, not on media based on pyruvate or glucose. However, acceleration of death by pyruvate was expressed on glycerol, glucose or pyruvate media. Cyclic $3^{\prime}, 5^{\prime}$ AMP (O.I mM), but not ATP, ADP or AMP, prevented substrate-accelerated death if it was free from other contaminating nucleotides, but it did not much affect the extended lag characteristically shown by survivors of substrate-accelerated death.

These findings $(a)$ extend the analogy earlier proposed between substrate-accelerated death and a repression phenomenon; $(b)$ demonstrate that it resembles 'metabolic injury' in freezing damage and recovery from irradiation damage; in that death does not occur during the overt stress.

Nitrogen Fixation by Thiobacillus ferrooxidans Species. By MARY E. MACKINTOSH (Microbiological Research Establishment, Porton Down, Salisbury, Wiltshire)

The acetylene reduction test has been shown to be a useful method for testing the ability of certain micro-organisms to fix nitrogen although the production of ethylene in this test (determined by vapour-phase chromatography) is only presumptive evidence for the presence of a nitrogenase (Hardy, R. W. F. et al. (1968), Plant Physiology 43, I I85; Millbank, J. W. (1969), Archiv für Mikrobiologie 68, 32; Postgate, J. R. (1970), Journal of General Microbiology 63, 137).

Certain strains of Thiobacillus ferrooxidans (including NCIB 8455 and NCIB 9490) will reduce acetylene when grown in a nitrogen-free medium. Because the medium, a modification of Leathen's (Leathen, W. W., Kinsel, N. A. \& Braley, S. A. (1956), Journal of Bacteriology 72 , 700 ), is acidic ( $\left.\mathrm{pH}_{2} \cdot 2\right)$ the flasks in which the bacteria are grown must be sealed from the 
atmosphere with Suba-Seals to prevent absorption of ammonia which would otherwise provide a utilizable nitrogen source. The flasks before being sealed must be gassed with a nitrogencarbon dioxide enriched mixture, as $\mathrm{CO}_{2}$ is the sole source of carbon. Acetylene was prepared from calcium carbide and water and was injected through the rubber seal. The flasks were incubated at $30^{\circ}$. Analysis of samples which were taken over a period of 3 to 4 days showed a progressive increase in the amount of ethylene present. When the bacteria were grown in the presence of $\left(\mathrm{NH}_{4}\right)_{2} \mathrm{SO}_{4}$ there was no evidence of acetylene reduction.

The ability of thiobacilli to reduce acetylene when grown in a nitrogen-free medium and their incompetence to do so when grown in the presence of a fixed nitrogen source is preposed a presumptive evidence for the presence of a nitrogenase in these organisms. The fixation of nitrogen by the acidophilic thiobacilli has not been previously reported.

New Methicillin-resistant and Dependent Substrains of Pediococcus cerevisiae and Their Uptake of Benzyl Penicillin. By D. WIDDowson and P. J. WhITE (Department of Microbiology, University of Sheffield, S10 2TN)

A substrain of Pediococcus cerevisiae ATCC 808I (called CRD) dependent on methicillin for growth was developed by serial transfers of parent organisms (White, P. J. (I968), Journal of General Microbiology 50, 85-105). Four new methicillin-resistant substrains have been produced by serial transfer alone (MRD I-4) and four by treatment with $N$-methyl- $N^{\prime}$-nitro- $N$ nitrosoguanidine followed by serial transfer $\left(808 \mathrm{I} \mathbf{R} ; \mathbf{R}_{1} \mathbf{I} ; \mathbf{R}_{2} A ; \mathbf{R}_{2} 4\right)$. Substrains MRD I-4 show methicillin-dependence as well as resistance. The four substrains CR I-4 are revertants derived from CRD that are independent of methicillin but still resistant. None of the substrains has marked resistance to benzyl penicillin; 0.5 to $\mathrm{I} \cdot 0 \mu \mathrm{g}$. of antibiotic $/ \mathrm{ml}$. inhibited growth of all strains. In substrain CRD mucopeptide synthesis as well as growth was not penicillin-resistant yet was methicillin-resistant (Wilkinson, B. J. \& White, P. J. (1969), Journal of General Microbiology 57, xv).

To measure uptake of benzyl penicillin, washed organisms were incubated at $37^{\circ}$ for $\mathbf{I}$ h. in $0 . \mathrm{I} \mathrm{M}$-phosphate buffer, $\mathrm{pH} 6.5$, containing $\left[{ }^{14} \mathrm{C}\right]$ benzyl penicillin $(0.05 \mu \mathrm{Ci} / \mathrm{ml} ., 0.25 \mu \mathrm{g} . / \mathrm{ml}$.), collected on membrane filters and washed three times with $5 \mathrm{ml}$. of unlabelled benzyl penicillin ( $1 \mathrm{mg}$./ml. in buffer). Radioactivity of each filter disk plus organisms was then measured. The parent organisms and every substrain showed similar uptakes, which reached a maximum ( 2 to $4 \mathrm{ng}$./mg. dry wt of organisms) after I h. incubation.

Uptake of benzyl penicillin after growth for $20 \mathrm{~h}$. with a subinhibitory concentration $(0.25 \mu \mathrm{g} . / \mathrm{ml}$.) was also measured. Organisms filtered from the culture and washed as before had uptakes similar to those quoted above. Organisms centrifuged after exposure to $\left[{ }^{14} \mathrm{C}\right]-$ benzyl penicillin (either in buffer or during growth), then washed twice with unlabelled penicillin ( $\mathrm{I} \mathrm{mg} . / \mathrm{ml}$.) before filtering, retained only 0.2 to $0.5 \mathrm{ng}$. of benzyl penicillin $/ \mathrm{mg}$. dry wt.

Mode of Action of Colicin D and Its Effects on Immune Cells. By K. Timmis and A. J. Hedges (Department of Bacteriology, University of Bristol)

Colicin $\mathrm{D}$ was previously reported to kill sensitive cells by inhibiting oxidative phosphorylation (Larionova, T. I. (1967), Antibiotiki 12, 1074). Using purified colicin D (Timmis, K., submitted for publication), we observed the following features of its action on sensitive cells (I) Lethal adsorption follows single-hit kinetics. (2) Usually about Ioo molecules are required to kill an average cell, although only 35 are needed in the presence of EDTA. (3) the lethal adsorption of colicin D is extremely sensitive to reaction conditions. (4) The sensitivity of indicator cells is drastically reduced by the addition of chloramphenicol: this effect is immediate. Chloramphenicol does not protect against the action of colicin E 2 (Timmis, K. \& Hedges, A. J., in preparation). (5) Colicin D specifically inhibits protein synthesis in sensitive cells as does colicin E 3 (Konisky, J. \& Nomura, M. (1967), Journal of Molecular Biology 26, I81) and does not inhibit DNA or RNA syntheses. Thus colicin D does not kill by inhibiting oxidative phosphorylation.

Although colicinogenic cells are immune to homologous colicin this immunity breaks down at high multiplicities, at least with colicin I, and the immune cells die with biochemical lesions similar to those observed in sensitive cells treated with colicin(Levisohnetal.(I968), Journalof 
Bacteriology 96, 8I I). This type of lethal immunity breakdown as not obtained with colicin D No loss of viability could be detected in col $\mathrm{D}^{+}$cells treated with great excesses of colicin although a reduction in growth rate was observed. Colicin D-resistant mutants were not affected by excess colicin and therefore the reduction in growth rate of col $\mathrm{D}^{+}$cells is specifically due to immunity breakdown, although this process is apparently different from that observed with colicin I.

The Development of Defined Growth Conditions for Pseudomonas aeruginosa. By J. Melling and M. R. W. Brown (Microbiological Research Establishment, Porton Down, Salisbury, Wiltshire, and Department of Pharmacy, University of Aston in Birmingham, Birmingham 4)

The composition and metabolism of bacteria undergo considerable variations as a result of changes in their environment. Therefore to investigate factors affecting the resistance of Pseudomonas aeruginosa (Brown, M. R. W. \& Melling, J. (1969), Journal of General Microbiology 59, 263-274) it was necessary to define growth conditions carefully in terms of both the chemical and physical nature of the environment.

A total of 2496 different media were examined for their ability to support growth of a washed inoculum of Pseudomonas aeruginosa. All media consisted of solutions of mineral salts and glucose with permutations of the constituents at the three concentration levels $0.1 \mathrm{M}, 0.01 \mathrm{M}, 0.001 \mathrm{M}$. Variations in the $\mathrm{pH}$ of the media were achieved using the acidic and basic salts of sodium potassium and ammonium phosphates. Media were observed daily and those showing visible growth were examined for $P$. aeruginosa by plating on milk agar (Brown, M. R. W. \& Foster, J. H. S. (1970), Journal of Clinical Pathology, 23, 172-177). The pooled information was analysed using a punch-card system to investigate interactions affecting growth. Results indicated a pH-concentration interaction which did not favour growth at low $\mathrm{pH}$ and high solute concentrations. The presence of potassium appeared to reverse this effect.

A medium which favoured growth of Pseudomonas aeruginosa was selected from the initial study and used in an investigation of $\mathrm{Na}^{+} / \mathrm{K}^{+}$interaction affecting growth and culture viability. Growth requirements for glucose and magnesium were investigated to obtain reproducible bacterial concentrations with various medium magnesium contents.

Conditions of aeration and agitation of cultures were examined for the effect on growth and an inhibitory effect of oxygen was observed when various $\mathrm{O}_{2} / \mathrm{N}_{2}$ mixtures were sparged into the medium. No such inhibitory effect was seen in nutrient broth cultures.

The Antibacterial Activities of Gallic Acid and Its Esters. By E. G. BEvERIDGE and I. BOYD (School of Pharmacy, Sunderland Polytechnic, Sunderland, County Durham)

This work was carried out in an attempt to relate the antibacterial activities of gallic acid and some alkyl esters to certain of their physical properties.

The concentrations required to produce a $98 \%$ kill in $30 \mathrm{~min}$. $($ LT $98=30$ ) of a washed suspension of Escherichia coli in phosphate buffer pH 6.5; minimum inhibitory concentrations and minimum bactericidal concentrations were determined in various media phosphate buffered to $\mathrm{pH} 6.5$. These each showed a decrease in the order gallic acid $>$ methyl gallate $>$ ethyl gallate $>$ propyl gallate $>$ butyl gallate $>$ amyl gallate. Hexyl and octyl gallates were not active even in saturated solution.

Log: $\log$ plots of time to give a $98 \%$ kill against concentration for each ester showed linear parallel regressions, i.e. similar concentration exponents for each ester. Gallic acid gave a concentration exponent significantly different from that of the esters.

Ester bactericidal activity $($ LT $98=30$ ) correlated well with water/oleyl alcohol partition coefficients, but less well with water solubility; the isopropyl and isobutyl esters in particular showed considerable deviations. Thus relative antibacterial activity may be connected with partitioning of the ester between the aqueous phase and the biophase.

Variation in effective concentrations of the esters is not related to differing degrees of ionization as the $\mathrm{p} K a$ values for dissociation of the first hydroxyl group were similar.

Gallic acid apart, the relative antioxidant activities of the esters were found to be 
similar, suggesting that the antibacterial mode of action is not closely related to antioxidant action.

It is of interest to note that equitoxic concentrations of the esters (LT $98=30$ ) lowered the surface tension of water by similar amounts. However, hexyl and octyl gallate solutions, giving similar depressions, could be prepared but they were not antibacterial.

\section{Red Cell Antigenic Modification and Neuraminidase Activity. By Mary McLoughlin and F. S. Stewart (Department of Bacteriology, Trinity College, Dublin)}

Influenza viruses and certain bacteria have been shown to possess, or produce, agents capable of modifying the surface of human and other mammalian red cells so that these are agglutinable by specific immune sera prepared against modified cells and also by agglutinins ( $T$ agglutinins) present in normal mammalian sera. Since many of the organisms producing the cell modifying agent (CMA) also produce an enzyme capable of breaking down red cell receptors for influenza virus (RDE) - an enzyme which has been identified as a neuraminidase (Gottschalk (1960), references, The Chemistry and Biology of the Sialic Acids) - it has been assumed, though without formal proof, that neuraminidase is also the agent responsible for antigenic red cell modification. This identification is the subject of the present investigation.

Preparations from various strains of streptococci and pneumococci were examined for cell modifying activity and for neuraminidase activity using bovine submaxillary mucin and human group $\mathrm{O}$ red cells as substrates. Neuraminidase activity was demonstrable only in CMA-positive strains and amongst these its presence and activity were clearly related to the CMA activity of the strain. The behaviour of active preparations of a strain of Pneumococcus (type 16) was examined in some detail. The cell modifying and neuraminidase activities of this strain were similar in the following respects: (I) heat lability, (2) pH optimum, (3) inhibition by high concentration of glucose in growth medium, (4) inhibition by immune serum, (5) precipitation by acetone, (6) elutability from human red cells, (7) filtration pattern on Sephadex G-200. Similar results have been obtained in respect of the CMA and neuraminidase activities of a CMA-positive strain of viridans streptococcus (63).

These findings support the postulated identity of the cell modifying agent and neuraminidase.

Recent Studies on the Vibrio cholerae Toxin. By J. Ungar, M. STanić, N. Chariatte and S. VARAllyAy (Research Department, Swiss Serum and Vaccine Institute, Berne, Switzerland)

Among the known toxic activities of the cholera toxin, two are of particular significance in the pathogenesis of cholera. Both are highly antigenic. The $T$ antigen causes the remarkable fluid accumulation in the bowel and the production of antitoxin, whereas the second one, the $\mathrm{V}$ antigen, elicits vibriocidal antibodies. Investigations have been made to define the two antigens immunologically and biochemically and to study their use as components in a cholera vaccine.

The filtrates of cholera fermentor cultures harvested in the logarithmic phase were processed by multimembrane electrodecantation. When the suspension was harvested before the end of the logarithmic phase, the filtrates contained a mixture of $T$ and $V$ antigens and only a very small amount of the endotoxin. The toxicity of the crude cholera toxin was determined by titration in the adult rabbit ileal loop. The toxicity of the crude toxin at $\mathrm{pH}_{7.2}$ to 7.5 using the 569 B strain was relatively low, 20 to 60 loop toxic units $/ \mathrm{ml}$ of the undiluted material. In addition to conventional concentration methods (ammonium sulphate precipitation and chromatography on DEAE-Sephadex A 50) the crude cholera filtrates were separated by multimembrane electrodecantation (MMED, Quickfit, England). This method permits the separation of crude cholera filtrates in an isoelectric and a non-isoelectric (decanted) component. The isoelectric material contains mainly the $\mathrm{T}$ component and small amounts of $\mathrm{V}$, whereas the non-isoelectric material contains mainly the $\mathrm{V}$ component and traces of $T$. The quality of the $T$ and $V$ antigens was determined by immunochemical and immunogenicity tests in rabbits. 
A Temperature-sensitive Cell Division Component in a Mutant of Salmonella typhimurium. By Nuzhat AHMed and R. J. RowbURY (Department of Botany and Microbiology, University College London)

Cell division in Escherichia coli is triggered by termination of rounds of DNA replication (Clark, D. J. (1968), Journal of Bacteriology 96, 1214). At least one division component is, however, formed throughout the division cycle (Smith, H. S. \& Pardee, A. B. (1970), Journal of Bacteriology ror, 901). We have isolated a temperature-sensitive mutant (strain 4a) of Salmonella typhimurium which may be altered in such a component. Organisms growing in nutrient broth at $25^{\circ}$ cease cell division immediately on transfer to $42^{\circ}$ and form long filaments. Organisms survive for $3 \mathrm{~h}$. before viability falls. DNA synthesis is normal at $42^{\circ}$. Septation resumes after a delay of $75 \mathrm{~min}$. (slightly less than one generation time) if filaments are shifted back to $25^{\circ}$. Eventually all the divisions delayed at $42^{\circ}$ take place. Protein synthesis is essential throughout the recovery period and septation is prevented by shifting to $42^{\circ}$ at any time during recovery. The recovery time is largely independent of the time at $42^{\circ}$ but is markedly affected by the medium. In MM or Casamino acids MM the recovery again takes slightly less than one generation time (I50 min. MM; $105 \mathrm{~min}$. Casamino acids MM). The immediate effect of the lesion suggests that the altered component is required for a late stage in cell division but the length of the recovery period suggests that it accumulates throughout most of the division cycle, remaining in a temperature-sensitive state until combined with another cell division factor in a terminal stage. The effect of the medium on the recovery time suggests that the temperature-sensitive component is not a D-period component. Under certain conditions the component is protected from heat inactivation by combination with a factor which still forms at $42^{\circ}$.

\section{Utilization of Organic Acids by Cocconeis diminuta. By K. E. CoOKSEY (Division of Functional Biology, Rosenstiel School of Marine and Atmospheric Science, Miami, Florida 33149, U.S.A.)}

The contrihution of benthic organisms to the productivity of shallow waters, such as exist off the coast of South Florida and on the Bahama Banks, is rarely considered. The metabolism of a marine benthic diatom, Cocconeis diminuta, is the subject of this communication.

Cocconeis diminuta assimilates organic compounds in the light and dark but cannot grow heterotrophically (Bunt, J. S. (1969), Journal of Phycology 5, 37). Experiments with radiolabelled compounds showed that acetate lactate and glycollate were assimilated and oxidized to $\mathrm{CO}_{2}$, both in the light and dark. Darkness favoured respiration, and light, incorporation into cell contents. Fractionation of cells which had metabolized $\left[2-{ }^{14} \mathrm{C}\right]$ acetate or $\left[\mathrm{U}-{ }^{14}\right]$ lactate in the light or dark indicated that both substrates gave rise to similar labelling patterns (Roberts, R. B., Cowie, D. B., Abelson, P. H., Bolton, E. T. \& Britten, R. J. (1955), Carnegie Institute of Washington Publication, no. 607, Washington, D.C.). Lipids were synthesized preferentially in the light and protein in the dark. Amino acid analysis of the protein residue fraction after fractionation showed that the glutamate family of amino acids was labelled very much more than other amino acids. Some radioactivity was found in asparate after $\left[2-{ }^{14} \mathrm{C}\right]$ acetate metabolism.

Key enzymes of the tricarboxylic acid cycle were detected in cell-free preparations. $\alpha$-Oxoglutarate oxidoreductase had a specific activity of 2 nmoles min. ${ }^{-1} \mathrm{mg}$. protein ${ }^{-1}$. This may account for the large flow of carbon from organic acids to glutamate and related amino acids.

$N\left(3,4\right.$,Dichlorophenyl) $N^{\prime} N^{\prime}$-dimethyl urea inhibited incorporation and stimulated respiration in the light. $1 \mathrm{IO}^{-2} \mathrm{M}$-Monofluoroacetate (MFA) inhibited respiration and incorporation in the light and dark, but $5 \times 10^{-4} \mathrm{M}$-MFA stimulated incorporation in the light.

Isocitrate lyase, but not malate synthase, was detected in autotrophically grown cells of Cocconeis diminuta. $\mathrm{NADH}_{2}$-oxidase was detected, but at levels which were possibly too low to allow a sufficient rate of ATP synthesis for growth in the dark. 
Changes in Enzymes and Intermediates of Glycolysis During the Growth Cycle of Aspergillus niger. By J. E. SMITH (Department of Applied Microbiology, Strathclyde University, Glasgow) and J. Valenzuela-Perèz (Colegio Civil Sur 452, Monterrey, N.L., Mexico)

The specific activities of certain enzymes of the Embden-Meyerhof-Parnas (EMP) and pentose phosphate (PP) pathways varied during the growth of Aspergillus niger as a function of the stage of the growth cycle and of the growth medium. The main fluctuations in enzyme levels occurred in advance of morphological evidence of sporulation.

Radiorespirometric studies indicated that the contribution of the PP pathways was highest in young non-sporulating mycelium, whereas the contribution of the EMP pathway was highest in sporulating mycelium of a similar physiological age.

The concentrations of the EMP intermediates were considerably higher in extracts of mycelium from sporulation medium than from non-sporulation medium at an early stage of development, well in advance of morphological evidence of sporulation.

Fractionation of Staphylococcal Membranes. By J. C. Measures (Microbiology Unit, Department of Biochemistry, University of Oxford)

The detergent, sodium lauryl sarcosinate (sarkosyl) has been used to isolate a membraneDNA complex from Bacillus megaterium (Tremblay, Daniels \& Schaechter (1969), Journal of Molecular Biology 40, 65. The method has been developed so that protoplast membranes of Bacillus megaterium and Escherichia coli can be fractionated (M. J. Daniels, personal communication). I have used this method to fractionate the protoplast membrane of Staphylococcus aureus PS 80 (NCTC 9789) and to look for membrane-DNA complexes in this organism.

Lysostaphin is used to prepare protoplasts and these protoplasts are lysed in conditions where they form a cadmium-sarkosyl-membrane complex. Membrane fractions are eluted from the complex with potassium ions and subsequently with deoxycholate (DOC). The elution profile is reproducible, the potassium ions eluting protein-rich fractions and the DOC lipid-rich fractions.

The DNA is mainly associated with four of the fractions eluted by potassium ions. Both newly synthesized DNA $\left(\left[{ }^{14} \mathrm{C}\right]\right.$ thymidine-labelled) and newly synthesized membrane $\left(\left[{ }^{3} \mathrm{H}\right] \mathrm{gly}-\right.$ cerol-labelled) appear in one particular fraction to a greater extent than these compounds labelled for a long period. Further, temperature shift experiments with strain Ps 80 harbouring a plasmid that is temperature-sensitive for replication (L. H. Johnston, personal communication) have shown that the plasmid DNA is eluted in the same fraction as the newly synthesized DNA. This fraction contains $35 \%$ of the sarkosyl-bound DNA, $25 \%$ of the sarkosyl-bound protein and $8.5 \%$ of the membrane lipid.

Integration and Excision Functions Specified by the Staphyloccal Penicillinase Plasmid. By

L. H. Johnston (Microbiology Unit, Department of Biochemistry, University of Oxford)

A penicillinase plasmid temperature-sensitive for replication has been isolated in Staphylococcus aureus PS 80 . Reversion of this plasmid to temperature stability was studied. Reversion seems to be due to integration into the chromosome. The evidence for this is: (i) in an outcross, by transduction, from a revertant all the plasmid markers are temperature-sensitive in the recipient, so reversion is not due to back-mutation; (ii) a revertant may be superinfected with a normally incompatible plasmid, showing that the putative membrane attachment site is probably vacant; and (iii) linkage between the reverted plasmid and markers believed to be on the chromosome has been demonstrated.

It is possible to transpose the gene for resistance to erythromycin (ero) from the plasmid to the chromosome (Novick, R. P. (1967), Federation Proceedings 26, 29). The integration frequency of the temperature-sensitive plasmid in such a strain is substantially increased. This seems to be due to a trans acting protein, since linkage between a reverted plasmid and the chromosomal ero is not obligatory. Furthermore, deletions of part of the plasmid were found to decrease integration frequency some II-fold. These deletions are located on a specific region of the plasmid and are believed to involve the loss of a gene, int, which produces a protein-mediating integration between a specific site on the plasmid and sites on the chromosome. A tentative map giving the locations of int and its site of action in relation to other known plasmid markers has been established. 
A superinfecting plasmid excises an integrated plasmid. It was shown that this is not merely a reverse of the integration event and that it is presumably due to a specific trans acting protein. The gene for this protein, xis, is distinct from int.

The similarities between these functions and those of the temperate phase $\lambda$ genome (Weil, J. \& Signer, E. R. (1968), Journal of Molecular Biology 34, 273; Guarneros, G. \& Echols, H., Journal of Molecular Biology (1970) 47, 565) are striking and it is proposed that temperate phage may have been the precursor of staphylococcal penicillinase plasmids.

Inducible Dehydrogenases and the Electron Transport Chain of Pseudomonas aeruginosa. By M. B. KemP (Microbiology Unit, Department of Biochemistry, South Parks Road, Oxford)

Inducible dehydrogenases for D- and L-lactate, L-mandelate, choline, sarcosine and D-allohydroxyproline have been identified in Pseudomonas aeruginosa (ATCC 15962). These enzymes were not linked to pyridine nucleotides but all were membrane-bound and could be assayed with oxygen or with dyes such as 2,6-dichlorophenolindophenol as acceptor.

The difference spectrum (dithionite-reduced minus ferricyanide-oxidized) showed that membrane fragments from aerobically grown cells contained cytochromes $b$ and $c$. When any one substrate was added to the membrane fragments and the suspension allowed to become anoxic, a fraction (often about $40 \%$ ) of the cytochrome $b$ became reduced; with more than one substrate, the reduction was not additive. Cytochrome $c$, however, was completely reduced by any substrate and complete reduction by 'endogenous substrate' could also be shown if the oxygen was removed by bubbling nitrogen through the suspension or if anoxia was mimicked by adding cyanide (I mM). This effect was still observed if the membrane fragments were prepared from cells which had been aerated in medium without any carbon source for $2 \mathrm{~h}$. or if the membrane fragments were dialysed overnight.

Terminal oxidase activity, assayed with reduced mammalian cytochrome $c(30 \mu \mathrm{M})$ or with ascorbate $(5 \mathrm{mM})$ and tetramethyl-p-phenylene diamine $(5 \mathrm{mM})$ was much more sensitive to inhibition by cyanide than was the overall activity of substrate oxidation assayed with D-lactate.

These results will be discussed in terms of the network model for the electron transport chain of Haemophilus parainfluenzae proposed by Smith \& White ((1962), Journal of Biological Chemistry 237, 1337) and by Smith et al. ((1970), Journal of Biological Chemistry 245, 5096).

The Degradation of Ethyl p-Hydroxybenzoate by Bacterium NCIB 8250. By E. G. BEVERIDGE and A. HART (School of Pharmacy, Sunderland Polytechnic, Sunderland, County Durham)

Bacterium NCIB 8250 failed to utilize various alkyl $p$-hydroxybenzoates as sole carbon sources but these compounds were metabolized, without the accumulation of aromatic or keto acid intermediates, when succinate was also included in the medium.

Cells grown with succinate as sole carbon source oxidized the esters only after a distinct lag while cells grown with succinate and an ester were adapted to $p$-hydroxybenzoate ester metabolism. The esters had similar inductive efficiencies. Replacement of succinate by fumarate, asparagine or acetate did not increase ester degrading activity of the cells. Adapted cells consumed a total of 7-8 $\mu$ mole $\mathrm{O}_{2} / \mu$ mole ethyl $p$-hydroxybenzoate depending on substrate concentration. Higher homologues showed greater uptakes. The oxidation was incomplete and was stimulated slightly by azide or 2,4-dinitrophenol and inhibited by $p$-chloromercuribenzoate. Examination of the oxidative ability of cells grown in the presence of ethyl $p$-hydroxybenzoate or other aromatic compounds suggested that ethyl $p$-hydroxybenzoate was metabolized via $p$-hydroxybenzoate or ethyl protocatechuate to protocatechuate and thence via $\beta$-ketoadipate, but that $p$-hydroxybenzoate and ethyl protocatechuate were unlikely to be intermediates of the same pathway.

Extracts from ethyl $p$-hydroxybenzoate adapted cells contained an NADPH-dependent $p$-hydroxybenzoate hydroxylase and protocatechuate 3,4-oxygenase. The latter enzyme did not oxidize ethyl protocatechuate. Ethyl $p$-hydroxybenzoate was not detected spectrophotometrically either in the presence or absence of NADH or NADPH. However, in the respirometer, ethyl $p$-hydroxybenzoate was oxidized very slowly and then more rapidly on prolonged 
incubation. Addition of NADH or NADPH had little effect. Hydrolysis of the ester to $p$-hydroxybenzoate and slow ring fission occurred but no $\beta$-ketoadipate accumulation was detected. This hydrolysis was performed slowly by extracts of cells grown with succinate alone which also contained very low levels of protocatechuate 3,4-oxygenase and $p$-hydroxybenzoate hydroxylase.

Pathways for ethyl $p$-hydroxybenzoate oxidation are suggested.

\section{POSTSCRIPT TO THE PORTON DOWN MEETING OF THE SOCIETY ON 4 AND 5 JANUARY 1971}

The following paper was presented at short notice by Dr W. E. Hornby (University of St Andrews) in place of Professor E. M. Crook (Medical College of St Bartholomew's Hospital). The abstract was caught up in the postal strike and not received till after the Proceedings had gone to press (Journal of General Microbiology 65, xii)

Modification of Enzymes for Therapeutic, Analytical and Industrial Usage. By W. E. HoRnBY (Department of Biochemistry, University of St Andrews, St Andrews, Fife)

The usefulness of enzymes in therapeutics, industry and analysis is widely recognized. Unfortunately their full potential value in these fields may not be realized due to a number of factors, among which are high initial cost of purified enzymes, their limited stability under the conditions in which they are normally used and the difficulties often encountered in recovering the enzymes for further use. These limitations can be partly overcome by the immobilization of purified enzymes and their use in this modified form. The advantages obtained from using enzymes in this way derive mainly from their enhanced stability and the ease with which they can be recovered from their reaction mixtures, making possible repeated use of the same enzyme preparation. Furthermore, the immobilization of an enzyme imparts a greater flexibility in the way in which the enzyme can be used; thus enzymes immobilized by attachment to either beads or fibres have been used in both continuous feed stirred reactors and packed beds, and enzymes attached to porous sheets or to the inside surface of tubes have been used in continuous flow-through processes.

Enzyme immobilization can also modify some of the properties of the enzyme. For example, displacement of the pH-activity curve of an enzyme occurs when it is immobilized either in or on a charged matrix. This effect can be utilized where an enzyme is required to effect catalysis at a $\mathrm{pH}$ different from its $\mathrm{pH}$ optimum. On a suitably charged matrix the $\mathrm{pH}$ optimum of the enzyme may be made to coincide with the $\mathrm{pH}$ of the reaction mixture. The physical nature of the support matrix can also affect the activity of the immobilized enzyme by causing partition of either substrate or inhibitor between the reaction mixture and the phase of the enzyme. The $K_{1}$ for aromatic inhibitors of invertase is decreased when the enzyme is immobilized by covalent attachment to polystyrene. Partition effects of this type could be exploited for enzymes with hydrophobic substrates; by immobilization on a support such as polystyrene the effective $K_{m}$ of the enzyme would be decreased. Finally, in the case of depolymerizing enzymes, immobilization often affects the way in which the enzyme degrades its polymeric substrate; thus immobilization of $\alpha$-amylase on either cellulose or polystyrene changes the amylolytic process from a multichain mechanism to a single-chain mechanism.

Enzymes can be immobilized by direct chemical attachment to a support or by indirect chemical attachment through other molecules. Ficin has been immobilized by direct chemical coupling through the carboxyl group of CM-cellulose and also by indirect coupling through the terminal carboxyl group of a polypeptide of $\gamma$-aminobutyrate, which had been attached to the CM-cellulose through its terminal amino group. The characteristics of the support are unchanged by indirect chemical coupling but the effects of immobilization on the enzyme are moderated. The specific proteolytic activity of bound ficin increases when the length of the poly- $\gamma$-aminobutyrate link is increased. Likewise, invertase has been directly coupled to succinylated polyaminostyrene and indirectly coupled to the same support through a poly- $\gamma$ aminobutyrate link. Again the properties of the support were unchanged, but the effect of the support on the partition of aromatic molecules between the bulk of the reaction mixture and the enzyme phase was moderated, the $K_{1}$ for aromatic inhibitors increasing when the length of the poly- $\gamma$-aminobutyrate link was increased. 